\title{
THE PROTEINS OF NORMAL URINE II. FROM THE URINARY TRACT *
}

\author{
BY \\ GREGOR H. GRANT \\ With the Technical Assistance of PHiLiP H. EVERALL \\ From the Department of Pathology, the Royal Salop Infirmary, Shrewsbury
}

(RECEIVED FOR PUBLICATION JUNE 26, 1959)

Normal urine contains traces of many different proteins. These proteins include:

(1) Plasma proteins entering the urine from the blood through the glomeruli.

(2) Urinary tract proteins from the glands or shed cells of the urinary tract from the kidney tubules downwards. One protein, the mucoprotein of Tamm and Horsfall (1952), has been described as from this source.

(3) In the male, seminal proteins from the genital tract and in particular from the prostate and bulbo-urethral glands, which open directly into the urethra. Several proteins have been described in seminal plasma (Ross, Moore, and Miller, 1942).

Immunochemical methods of analysis have made it possible not only to demonstrate such proteins in normal urine, but even to investigate their origins. The detection in normal urine of most of the plasma proteins (exceptions include fibrinogen and $\beta$-lipoprotein) was described previously (Grant, 1957): evidence for the presence of proteins from other sources is now presented.

\section{Materials and Methods}

Urines Examined.-Individual and pooled samples from four normal men, four normal women, and five children, three boys and two girls, aged 4 to 11 , were investigated. They were all members of the laboratory staff or of their families. Simple precautions were taken to avoid contamination, and the samples were preserved with sodium azide $(1 \mathrm{~g}$. per litre). They were concentrated by ultrafiltration under negative pressure through Visking dialysis tubing as previously described, but, instead of tubing of $\frac{3}{4}$ in. flat width, longer lengths of the narrower $\frac{3}{8}$ in. flat width tubing $\dagger$ were used because of its

*Based on a paper read at the combined meeting of the Association of Clinical Pathologists and of the Association of Clinical Biochemists in London on October 4, 1958. Part I was read at a meeting of the Association of Clinical Pathologists at Torquay on October 12, 1957 (J. clin. Path., 1957, 10, 360).

†Obtainable from Hudes Merchandising Corporation, 52, Gloucester Place, London, W.1. ability to withstand the pressure without support (Everall and Wright, 1958). After the urine had been concentrated about 50 times, it was centrifuged and the supernatant was further concentrated in a fresh length of dialysis tubing to give a final concentration of about 1,000 times. If it is concentrated in a single stage, the final product is often too viscous to allow any precipitate to settle.

Tamm-Horsfall Mucoprotein.-This was prepared from normal urine (preserved with sodium azide, $1 \mathrm{~g}$. per litre) by adding an equal volume of $1.16 \mathrm{M}$ $\mathrm{NaCl}$. The precipitate was washed twice with $0.58 \mathrm{M}$ saline, and then dialysed against distilled water containing $1 \mathrm{~g}$. per litre sodium azide, until tests for chloride became negative. Before analysis it was dialysed against the appropriate buffer.

Such preparations when freshly made will not diffuse through agar even in an electric field. On standing, however, they become in time freely diffusible and suitable for use in immunochemical agar gel tests.

Semen.-Samples were available from patients who were referred to the laboratory from the infertility clinic and subsequently found to be normal.

Antisera.-These were prepared in rabbits against (1) concentrated normal male urine colloids ; (2) concentrated normal female urine colloids; (3) TammHorsfall mucoprotein freshly prepared as above ; and (4) normal human semen.

At least two rabbits were used for each ; the courses of injection were as previously described; and the antisera were preserved with sodium azide $(1$ in 1,000). Before use antibodies against serum proteins were removed by absorption.

This absorption proved to be unexpectedly difficult, for the antisera were found to contain antibodies against proteins which are present in exceedingly low concentrations in normal human serum. Human serum, concentrated four times by the same technique as that used for concentrating urine colloids, was therefore used for their absorption, 1 volume of concentrate to 10 volumes of antiserum. The absorbed antisera then gave no precipitin reaction with an equal volume of human serum concentrate, 
an equal volume of fresh serum, or $1 / 20$ volume of fresh serum.

In addition to the above antisera, rabbit antisera against normal human serum proteins were required for the analyses of normal human serum run in parallel with the urine analyses to indicate the relative mobilities of the serum and urinary tract proteins.

Immunochemical Analyses.-For the simple agar gel precipitin tests (Ouchterlony, 1949) Petri dishes containing $p H 7.4$ phosphate agar were used (Gell, 1955). Then $27.5 \mathrm{~g}$. potassium dihydrogen phosphate, $17.0 \mathrm{~g}$. sodium chloride, $8.0 \mathrm{~g}$. potassium hydroxide, and $15 \mathrm{~g}$. agar were dissolved in 2 litres of distilled water and filtered while hot through a bed of "hyflo super cell" under reduced pressure. Sodium azide was added to give a final concentration of $1 \mathrm{~g}$. per litre and the agar sterilized at $5 \mathrm{lb}$. pressure for 15 minutes.

The immuno-electrophoretic analyses were carried out by the method of Grabar and Williams (1955) modified as previously described (Grant, 1957).

\section{Results}

Analyses with Antisera against Normal Urine Colloids Absorbed with Normal Serum.-These antisera should demonstrate every urine protein except those in blood serum.

Simple Diffusion-precipitin Analyses.-Fig. 1 illustrates such an analysis; two samples of male urine concentrate, two samples of female urine concentrate, and some salt-precipitated TammHorsfall mucoprotein have been allowed to react

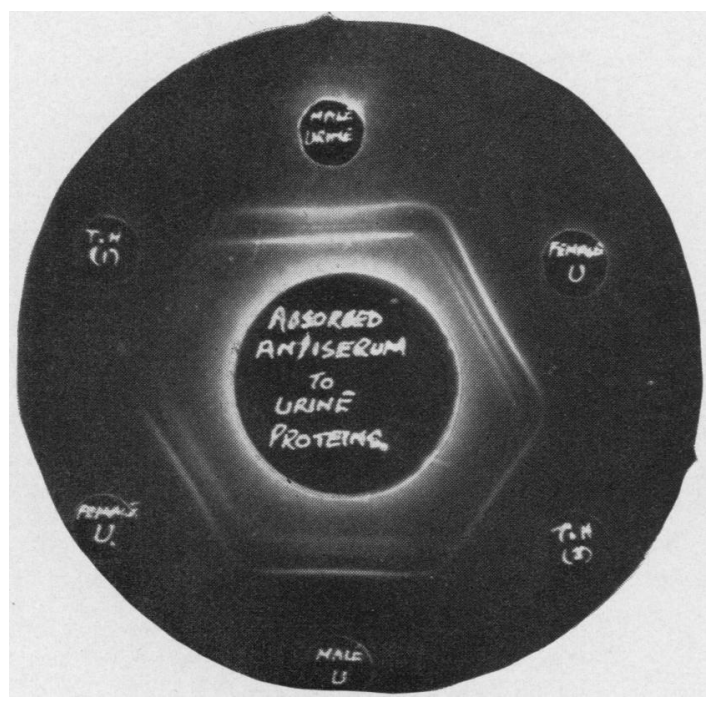

FIG. 1.-Comparison between non-serum proteins of male urine, female urine, and Tamm-Horsfall mucoprotein in ceripheral cups. In the centre cup is shown antiserum against normal male urine colloids (absorbed with normal human serum). [(Direct print of Ouchterlony plate stained with azocarmine.)

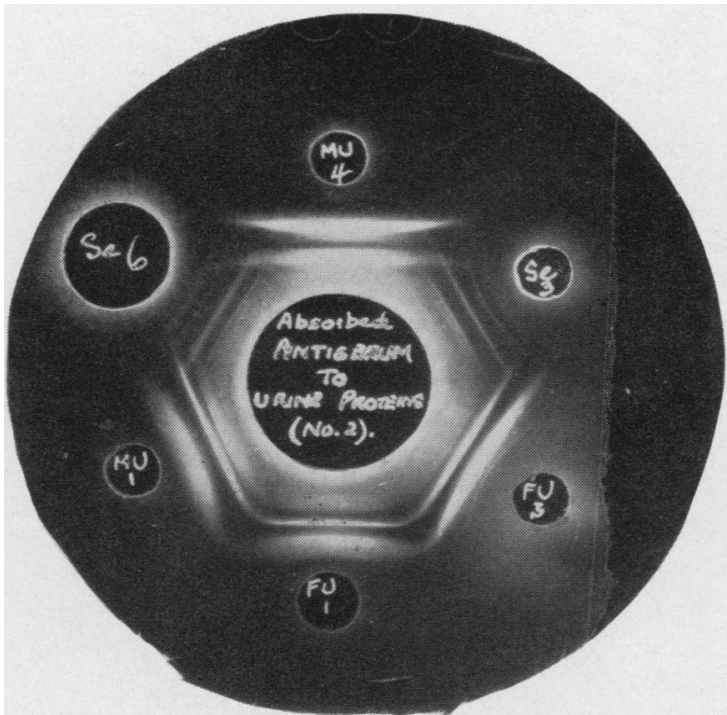

FIG. 2.-Comparison between male (M.U.), female urine colloids (F.U.), and semen (Se), using the same antiserum. (Similar direct print.)

with an antiserum made against male urine colloids, prepared and absorbed as described above. The urine concentrates form multiple precipitin lines, two of which are particularly well marked. One of the latter gives the "reaction of identity" with the mucoprotein preparation. Similar results were obtained with the antisera made against female urine concentrates.

In Fig. 2 urine concentrates have been compared with normal semen using a similar antiserum. As expected the antiserum contains antibodies to several seminal proteins and these proteins are only minor components of the urine protein; their precipitin lines cut those of the main urinary tract proteins, including that due to the Tamm-Horsfall mucoprotein, a protein evidently absent from semen.

Similar analyses, using also antisera made against female urine concentrates, led to a further and unexpected finding, namely, several trace components common to semen and to female urine as well as to male urine. On the basis of these preliminary experiments three groups of components can be distinguished :

(1) Components common to male and female urine but not present in semen: these presumably arise from the upper urinary tract; they include the mucoprotein of Tamm and Horsfall as well as the other principal components.

(2) Components common only to male urine and semen: they are apparently only present in traces and presumably arise from the genital tract. 


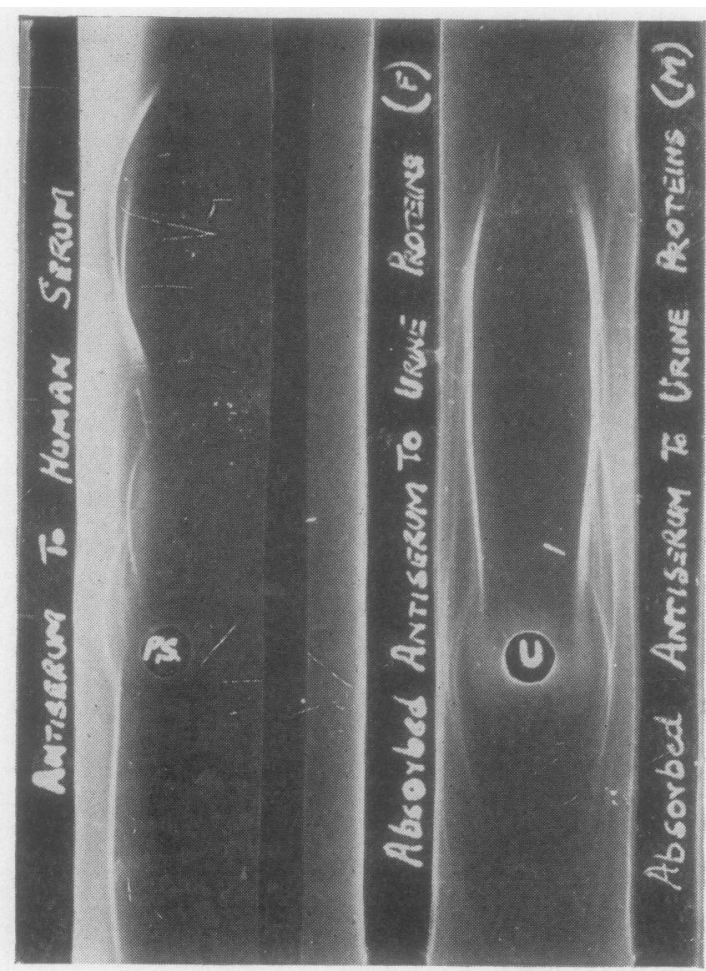

FIG. 3.-Immuno-electrophoretic analysis of male urine colloids (U.) with antisera against male non-serum urine proteins (M.) and female non-serum urine proteins (F.). On the left some normal pooled human serum (P.S.) has been analysed with its homologous antiserum for comparison. The additional line with the male antiserum is prostatic in origin. (Direct print after staining with azocarmine.)

(3) Components common to male urine, female urine, and semen: they seem to be present only in traces and possibly arise from the urethra ; the female urethra has glands similar to, although less abundant than, those of the male urethra. (Normal cervical mucus appeared to give no reaction with the antisera.)

Immuno-electrophoretic Analyses.-Urine concentrates from either sex were again found to give very similar results whichever anti-urine-protein antiserum was used (Fig. 3). Such analyses suggest that there are at least a dozen antigenic components other than serum proteins in male urine, most of them giving only faint precipitin lines.

Analyses with Antisera against Normal Urine Colloids Absorbed with 1/10 Volume of Semen and with Serum.-These antisera should precipitate only the first group of components listed above, namely, those arising from the upper urinary tract (the kidneys, ureters, and bladder).
The two sexes gave a similar pattern, which includes the principal lines seen in the previous analyses. It was not significantly changed whether the absorbed antiserum used had been made against male or against female urine colloids. But, as commonly occurs in such immunochemical analyses, the results using different ratios of antigen (urine concentrates) to antiserum or using similar antisera from different rabbits, although fundamentally similar, differed in the relative densities of the precipitin lines. A composite diagram (Fig. 4) was therefore made from a number of such

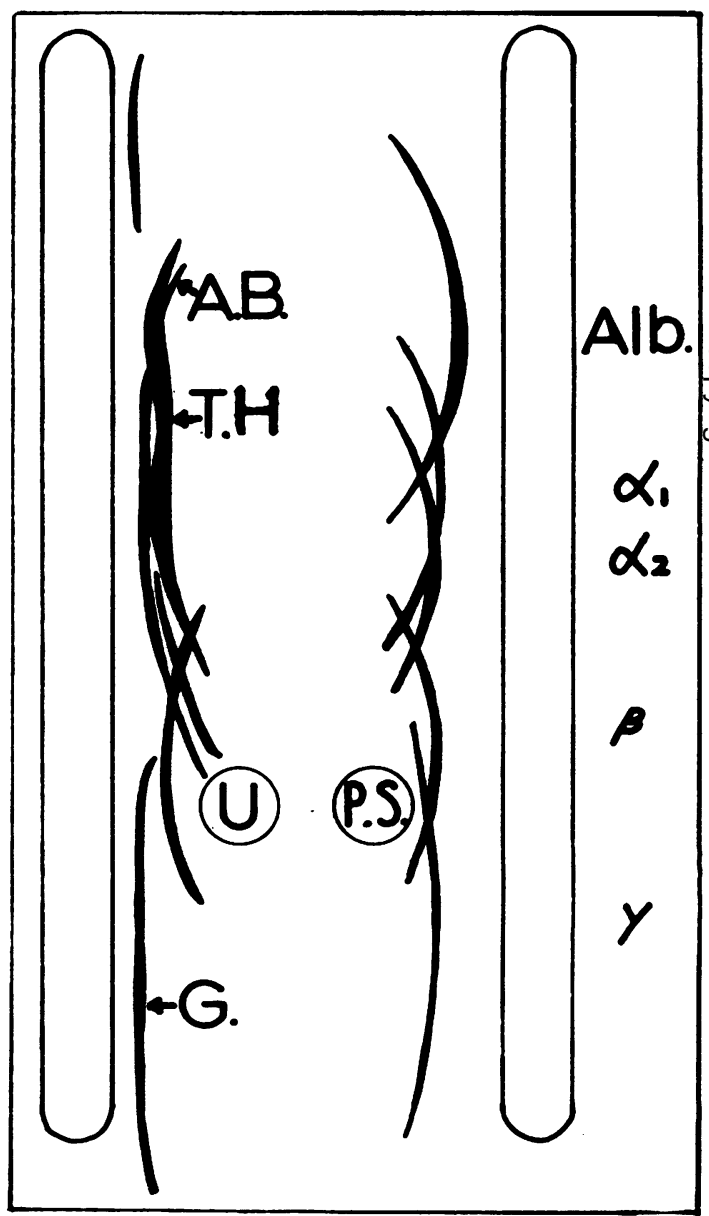

FIG. 4.-Diagram of immuno-electrophoretic analysis of upper urinary tract non-serum proteins (left) with outline of blood serum protein pattern (right) for comparison. $\quad$ U. =urine colloid concentrate. P.S. = pooled normal blood serum. Left trough $=$ antiserum against male urine colloids, absorbed with serum and semen. Right trough $=$ antiserum against normal human blood serum. 


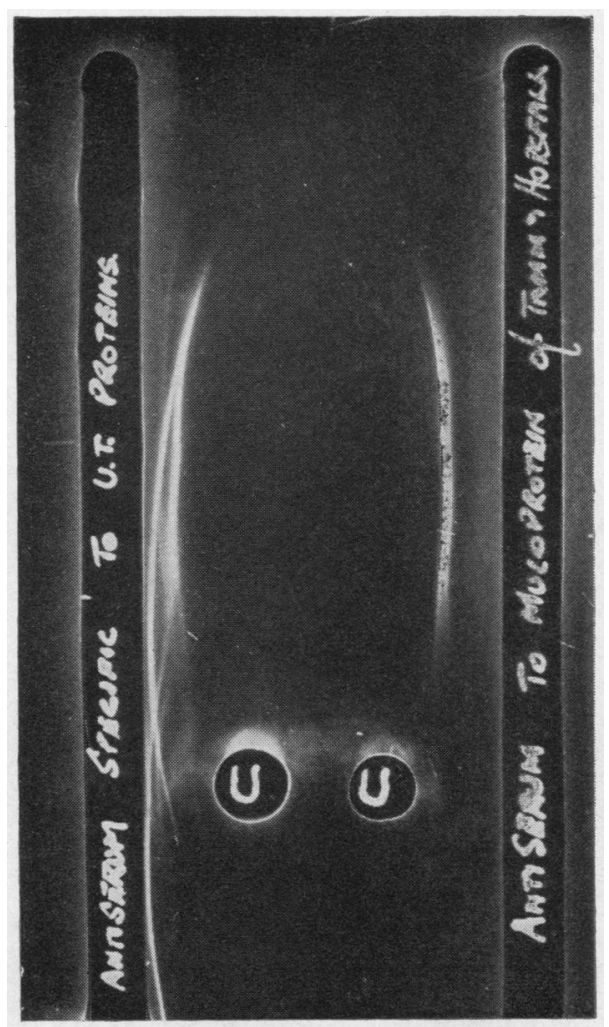

FIG. 5.-Identification of component antigenically similar to Tamm-Horsfall mucoprotein. U.=male urine concentrate. Left trough = antiserum against male urine colloids absorbed with serum and semen. Right trough $=$ antiserum to the salt-precipitated protein of Tamm and Horsfall.

analyses as that illustrated on the left of Fig. 5. Comparison with serum proteins analysed on the same plate allows a rough estimate of the mobilities of these urine proteins using the data of Williams and Grabar (1955).

Of the six precipitin lines, that labelled T.H. in Fig. 4 was predominant in all analyses. The line $A B$ and occasionally the line $G$ were nearly as dense with certain antisera. The remaining lines were always faint.

The line T.H. corresponds to the saltprecipitated mucoprotein of Tamm and Horsfall (Fig. 5). It has two humps with maxima as shown and sometimes it extends faintly to a position opposite the cup, probably owing to adsorption to material remaining unmoved.

Analyses with Antisera against Normal Semen Absorbed with Normal Human Serum.-These antisera should react with all seminal proteins not common to blood serum. Proteins of this type in the urine presumably arise from the urethra or male genital tract: they form the second and third groups of components classified in the preliminary experiments above.

Simple Diffusion-precipitin Analyses.-In Fig. 6 the use of this type of antiserum to compare the antigenic components of male urine, female urine, and semen is illustrated. It confirms that there are about four components common to semen and to female urine as well as to male urine. The absence of the Tamm-Horsfall mucoprotein from semen was also confirmed.

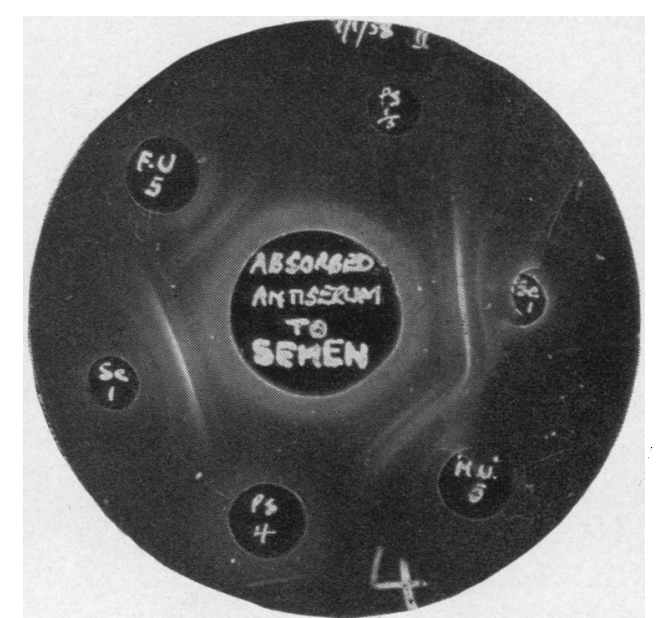

FIG. 6.-The non-serum proteins common to urine and semen. Centre shows antiserum against normal semen (absorbed with normal human serum). M.U.= male urine colloid concentrate. F.U. = female urine colloid concentrate. Se=semen. P.S. = pooled normal serum control.

Immuno-electrophoretic Analyses.-As these components are only present in traces, the urine colloids were concentrated 4,000 times before analysis. It was then found that the two most intense precipitin lines common to both male and female urine had mobilities in the $\alpha \beta$ serum globulin range and in the $\gamma$ serum globulin range respectively. In addition male urine has two denser lines of prostatic origin with $\alpha$ and $\beta$ mobilities. Fig. 7 shows these lines diagrammatically; inconstant fainter lines have been omitted.

Analyses with Antisera against Normal Semen Absorbed with Female Urine Colloids and Blood Serum.-These antisera should react only with the second group of components, the specific proteins of semen, and not with those proteins which arise from the blood or the urinary tract. 
In Fig. 8 a normal male urine concentrate has been compared with samples of normal semen, prostatic fluid, and seminal vesicle fluid, using an antiserum made against normal semen and then absorbed with one-tenth of its volume of normal female urine concentrate $(\times 1,000)$ as well as with serum. The female urine colloid concentrate used for absorption was pooled from six donors. The figure shows that there are two specific seminal proteins in this sample of male urine and that both are prostatic in origin.

Analyses with Antisera against Salt-precipitated (Tamm-Horsfall) Mucoprotein Absorbed with Normal Human Serum.-These antisera were used to identify the Tamm-Horsfall component in normal urine colloid concentrates as in Fig. 5, to

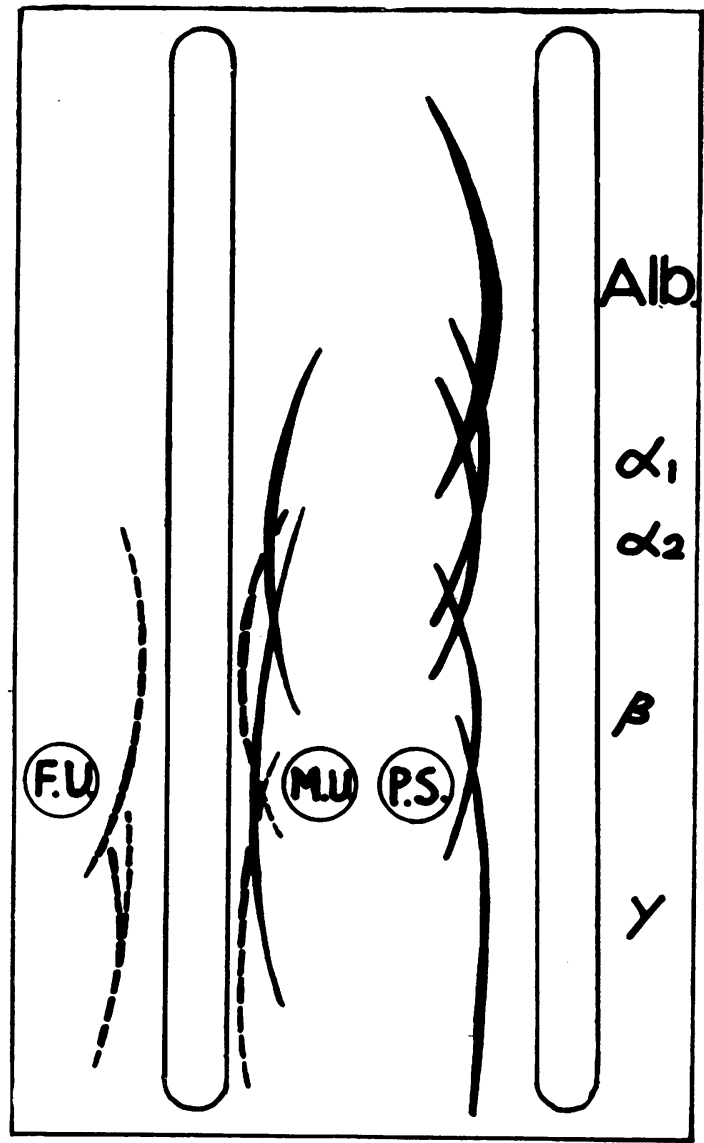

FIG. 7.-Diagram of immuno-electrophoretic analysis of lower urinary tract non-serum proteins (left) with outline of normal blood serum protein pattern (right) for comparison. M.U.= male urine colloid concentrate. F.U. $=$ female urine colloid concentrate. P.S. = normal blood serum. Left trough $=$ antiserum against normal semen absorbed with normal human serum. Right trough $=$ antiserum against normal human blood serum.

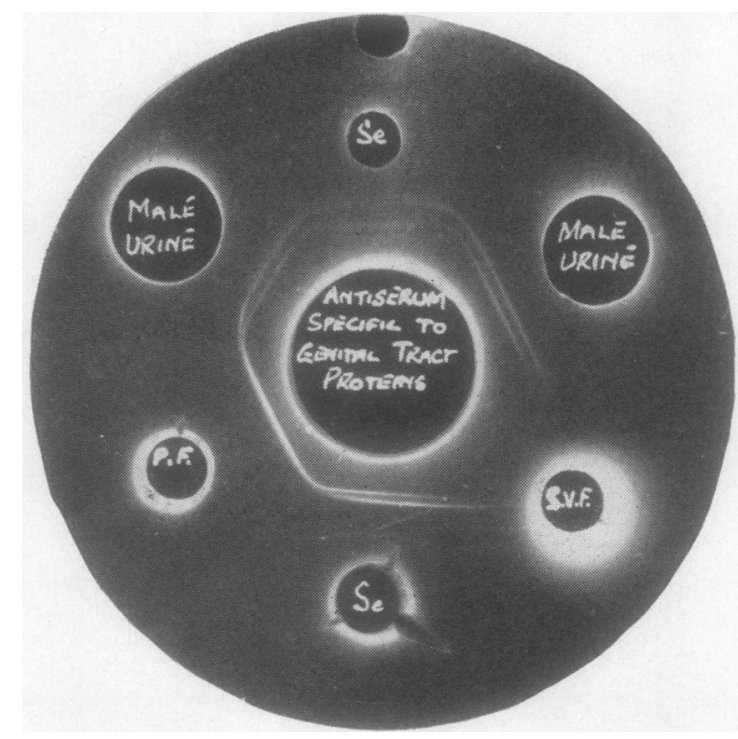

FIG. 8.-Specific seminal proteins in male urine. Centre shows antiserum against normal semen absorbed with pooled female urine concentrates as well as normal serum. Se $=$ semen. P.F. = prostatic fluid (collected post mortem from the outer cut surfaces of the lateral lobes). S.V.F.=seminal vesicle fluid (collected post mortem).

compare it with the salt-precipitated preparations, and to study the cause of the elongation of their precipitin lines.

The diffusible form of the salt-precipitated mucoprotein was found to resemble the antigenically similar component of urine colloid concentrates in having the mobility of an $\alpha$ serum globulin, that is to say, a mobility much slower than the preparations studied by Tamm and Horsfall after freezing and drying. The line was also elongated but without the humps.

The elongated shape of the precipitin lines seen in Figs. 3 and 5 suggests that in normal urine this mucoprotein is not a single protein, but, like $\gamma$ globulin, a mixture of closely related ones, identical antigenically but differing in mobilities. The two humps suggest that there are two main forms. The possibility that the appearance is due to adsorption on to $\alpha$ serum globulins seems ruled out by the low concentrations of these globulins in urine (Grant, 1957). Adsorption on to the agar was excluded by two-dimensional electrophoresis (Fig. 9). A drop of concentrated urine colloids was placed in a hole near one corner of a rectangular plate of barbiturate agar and submitted to electrophoresis in the usual way. The plate was then turned through a right angle and submitted to electrophoresis a second time so that the proteins moved up between troughs previously cut 


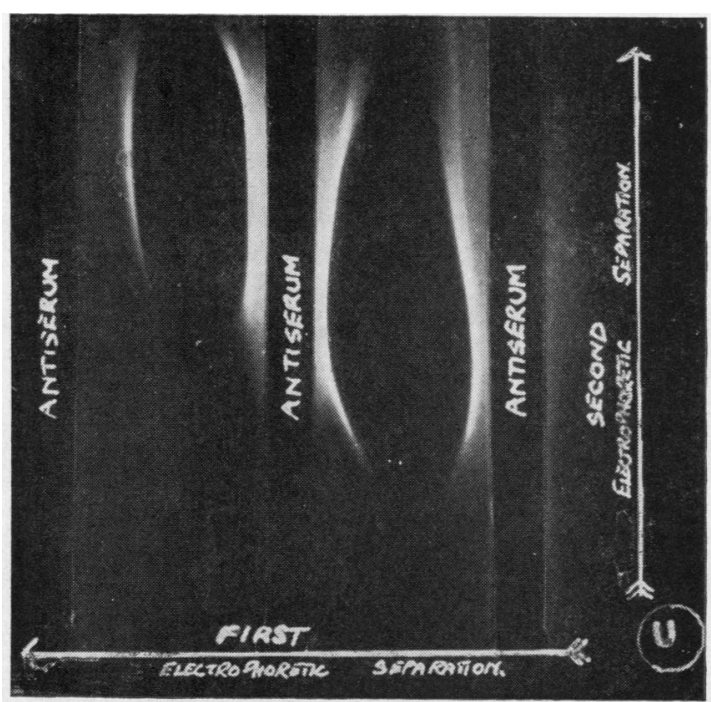

FIG. 9.-Demonstration of heterogeneity of Tamm-Horsfall protein in normal urine colloid concentrate (see text).

in the plate. Finally the troughs were filled with an antiserum made specifically against the mucoprotein. It will be seen that the fractions with the greatest mobilities in the first run also have the greatest mobilities in the second run. If the protein had been homogeneous and adsorbed on to the agar, all the precipitin curves should have been similar.

\section{Discussion}

The analyses described above suggest that normal urine contains, in addition to plasma proteins, many antigenic components which are not detectable in blood and which arise from different parts of the urinary tract. Furthermore, urine is so complex as to make it probable that other components not described above would be detected, if an even more sensitive technique were used. This multiplicity of components may well explain the difficulties which have been met in the attempts to explain the relation, if any, between urinary calculus formation and the excretion of protein by the urinary tract.

If these urinary tract proteins occur also in blood, they must be in exceedingly small concentration. The failure to detect them immunochemically indicates that their concentrations must be less than about $1 \mathrm{mg}$. per $100 \mathrm{ml}$. Furthermore, rabbits repeatedly injected with blood serum over many months did not make detectable amounts of antibodies to them; such antisera after being absorbed with one-tenth volume of normal pooled serum failed to react with male or female urine concentrates on an Ouchterlony plate.

Owing, however, to the high normal glomerular filtration rate (180 litres per day), very small concentrations could give easily detectable amounts in urine concentrated a thousandfold, if the components were completely excreted by the kidney and not almost entirely retained like ordinary plasma proteins: their concentrations in the urine colloid concentrates could be some 100,000 times that in the blood. In view of this the possibility of the presence of these components in minute amounts in the blood cannot be regarded as wholly excluded.

Normal urine colloids are known to include free as well as protein-attached polysaccharides (Rigas and Heller, 1951 ; Kerby, 1954 ; Hamerman, Hatch, Reife, and Bartz, 1955 ; Markham, Jacobs, and Fletcher, 1956; Heremans, 1958). This can be illustrated by submitting a urine colloid concentrate to paper electrophoresis and staining the paper with Alcian blue for polysaccharide followed by azocarmine for protein: at least two bands due to free acid polysaccharides can be demonstrated migrating in front of the albumin (Heremans, Vaerman, and Heremans, 1959). These free polysaccharides do not, however, appear to be antigenic, for no precipitin lines were obtained when the appropriate areas of filter paper were tested with the antisera. Perhaps all the antigenic components are proteins, some no doubt having large polysaccharide radicals attached; the possibility, however, remains that normal urine contains some free polysaccharides sufficiently complex to be antigenic.

Tamm and Horsfall (1952) found normal urine to contain about $25 \mathrm{mg}$. per litre of their mucoprotein, so forming a considerable proportion of the traces of protein known to be present. It was not therefore surprising to find that the most prominent non-serum protein precipitin line should give the "reaction of identity" with this salt-precipitated mucoprotein.

But, as has been shown, the shape of this line and the results of two-dimensional electrophoresis indicate that there are at least two forms of this protein in normal urine. If several interchangeable forms differing in molecular size can exist, it would help to explain why each published method for the isolation of the mucoproteins of normal urine seems to result in a product with different properties. Tamm and Horsfall (1952) used salt precipitation and isolated a mucoprotein with thread-like molecules of molecular weight 7 million having an electrophoretic mobility much 


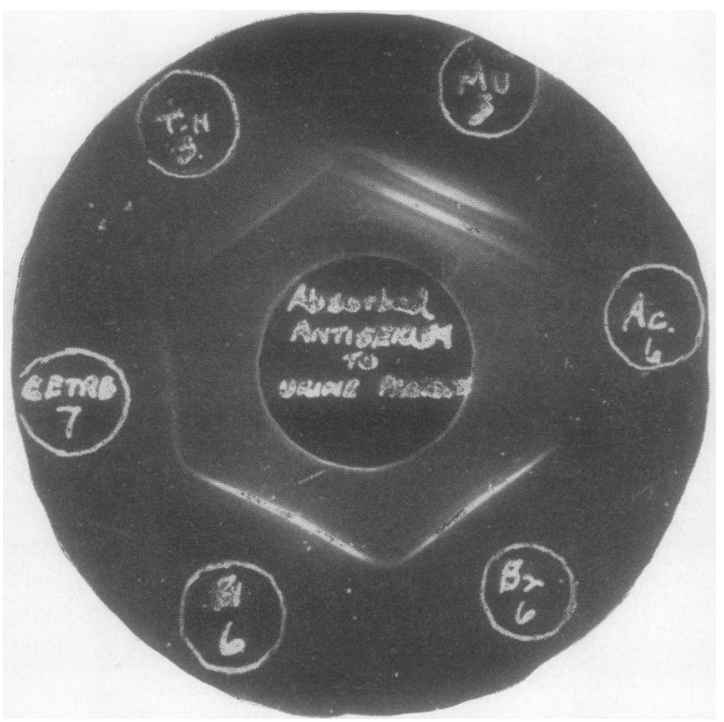

FIG. 10.-Comparison between male urine colloid concentrate (M.U.) and mucoprotein preparations precipitated with sodium chloride (T-H), cetyl trimethyl ammonium bromide (cetab), and benzoic acid $\left(B_{1}\right.$ and $\left.B_{2}\right)$. Centre shows antiserum to male urine colloids (absorbed with human blood serum).

greater than that of albumin. Boyce, Garvey, and Norfleet (1954) describe the mucoprotein in concentrated normal urine colloids as partly insoluble, their "uromucoid," and partly soluble with the mobility of an $\alpha$ serum globulin, in agreement with the findings above. Anderson and Maclagan (1955) isolated their mucoprotein by precipitation with benzoic acid and found it to have the electrophoretic mobility of an $\alpha$ serum globulin and a molecular weight of about 30,000 (see Maclagan and Anderson, 1958). Di Ferrante and Rich (1956) used cetyl trimethyl ammonium bromide as precipitant. Their product resembled Tamm and Horsfall's product in its biological activity and chemical analysis (Di Ferrante and Popenoe, 1957), but was found by Maxfield (1958) to have a molecular weight of 1.5 million.

Presumably all these forms have a precursor in common. Their antigenic similarity (see Fig. 10) is good evidence that this is so, as well as the fact that our fresh preparations of the salt-precipitated protein, when diffusible, have $\alpha$ serum globulin mobility like the corresponding component in concentrated urine colloids; they also have the same ultra-violet adsorption spectrum (maximum $277 \mathrm{~m} \mu$ ) as the preparations of Tamm and Horsfall and of Di Ferrante and Rich.

The physical differences between the different preparations are presumably due to varying degrees of polymerization, but it is not clear which is the naturally secreted form, a small molecular form which polymerizes during isolation, or a large molecular form which breaks down. Another possibility is that the antigenic components with $\alpha$ serum globulin mobility are protein moieties of an originally more complex mucoprotein or mucopolysaccharide.

The heterogeneity of this mucoprotein fraction is evidently the main reason why electrophoresis of concentrated normal urine colloids produces a blurred pattern in the $\alpha$ serum globulin region, both by the moving boundary (Rigas and Heller, 1951) and by the paper (Slater and Kunkel, 1953) methods.

The precipitin lines of some of the minor urinary tract components also seem elongated and asymmetrical. This may be due to similar heterogeneity, or to absorption either to agar or to other proteins.

\section{Summary}

About 12 antigenic components, not detectable in normal serum, have been demonstrated immunochemically in normal urine.

These components, probably all proteins, are divisible into three groups:

(1) Those arising from the kidneys, ureters, and bladder. There are about six of these and they include all the principal non-serum proteins in normal urine.

(2) In the male, trace components from the genital tract, especially from the prostate.

(3) Trace components common to male urine, female urine, and semen, possibly arising in both sexes from the urethra.

The mobilities of the more prominent components have been studied by immunoelectrophoresis and compared with those of the principal serum proteins.

Included in the first group is the main nonserum protein of normal urine. It gives the "reaction of identity" with the main component of the proteins precipitated by sodium chloride (Tamm and Horsfall), benzoic acid (Anderson and Maclagan), or cetyl trimethyl ammonium bromide (Di Ferrante and Rich). The differences which do occur between these various mucoprotein preparations are probably due to varying degrees of polymerization.

This mucoprotein and possibly some of the other non-serum proteins are present in urine as groups of closely related proteins rather than as single substances.

We should like to thank Mr. G. Wright and Miss M. Carpenter for technical assistance and Mr. R. Ross for Figs. 4 and 7. 


\section{REFERENCES}

Anderson, A. J., and Maclagan, N. F. (1955). Biochem. J., 59, 638. Boyce, W. H., Garvey, F. K., and Norfleet, C. M. (1954). J. clin. Invest., 33, 1287.

Di Ferrante, N., and Rich, C. (1956). J. Lab. clin. Med., 48, 491. and Popenoe, E. A. (1957). Scand. J. clin. Lab. Invest., 10 Suppl. 31, p. 268.

Everall, P. H., and Wright, G. H. (1958). J. med. Lab. technol., 15, 209.

Gell, P. G. H. (1955). J. clin. Path., 8, 269. Grabar, P., and Williams, C. A. (1955). Biochim. biophys. Acta,
17, 67.

Grant, G. H. (1957). J. clin. Path., 10, 360.

Hamerman, D., Hatch, F. T., Reife, A., and Bartz, K. W. (1955). J. Lab. clin. Med., 46, 848.

Heremans, J. (1958). Rev. belge Path., 26, 264.
Heremans, J., Vaerman, J. P., and Heremans, M. Th. (1959). Nature (Lond.), 183, 1606.

Kerby, G. P. (1954). J. clin. Invest., 33, 1168.

Maclagan, N. F., and Anderson, A. J. (1958). Ciba Foundation Symposium on the Chemistry and Biology of Mucopolysaccharides, p. 284. Churchill, London.

Markham, R. L., Jacobs, J. H., and Fletcher, E. T. D. (1956). J. Lab. clin. Med., 48, 559.

Maxfield, M. (1958). Fed. Proc., 17, 106.

Ouchterlony, O. (1949). Lancet, 1, 346.

Rigas, D. A., and Heller, C. G. (1951). J. clin. Invest., 30, 853.

Ross, V., Moore, D. H., and Miller, E. G. (1942). J. biol. Chem., $144,667$.

Slater, R. J., and Kunkel, H. G. (1953). J. Lab. clin. Med., 41, 619.

Tamm, I., and Horsfall, F. L. (1952). J. exp. Med., 95, 71.

Williams, C. A., and Grabar, P. (1955). J. Immunol., 74, 158. 